\title{
Factors Influencing Farmers' Willingness to Pay for Weather Index Insurance Through Fuzzy-Set Qualitative Comparative Analysis: Insights from a Pilot in Jiangxi Province, China
}

\author{
Xue ZHANG ${ }^{\mathrm{a}}$, Zhihong LUO $^{\mathrm{a}, 1}$, Yeyin $\mathrm{WANG}^{\mathrm{b}}$, Song YI ${ }^{\mathrm{a}}$, Wei ZHANG ${ }^{\mathrm{a}}$, \\ Zhiming WU ${ }^{\mathrm{a}}$

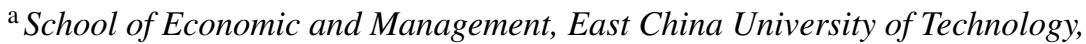 \\ Nanchang 330013, P. R. China \\ ${ }^{\mathrm{b}}$ School of International Education, Shandong Polytechnic College, \\ Jining 272067, P. R. China
}

\begin{abstract}
Weather index insurance plays an important role in helping farmers avoid their economic loss from weather risk. There is increasing numbers of pilot areas of weather index insurance in China while the studies show its take-up has been disappointing low in many other developing countries. This study aims to explore the status of weather index insurance and its processing problems in China through the factors influencing farmers' willingness to pay for Low-Temperature Index-based Mandarin Orange Insurance in Nangfeng County. The Fuzzy-Set Qualitative Comparative Analysis is conducted for the influencing factors, including strike level, premium, pay-out, planting cost, effect of low temperature, insurance claim process, trust in insurance and government subsidy. The result shows the combination of expensive premium, low payout, high planting cost, low government subsidy and distrust in insurance company causes farmers' unwillingness to pay for Low Temperature Index-based Mandarin Orange Insurance, among which distrust is core factor. Expensive premium, low payout, high planting cost and low subsidy from government are main influencing factors.
\end{abstract}

Keywords. Low-Temperature Index-based Mandarin Orange Insurance, Fuzzy-Set Comparative Qualitative analysis, Low-take up, Distrust, Expensive premium, Low payout, High planting cost, Low government subsidy

\section{Introduction}

The implications of climate change for agriculture and food are global concerns, and they are very important for China [1]. In order to help farmers avoid their economic loss from weather risk, Chinese government actively takes measures to enhance agricultural

\footnotetext{
${ }^{1}$ Corresponding Author: Zhihong LUO; E-mail: luozhh@ecut.edu.cn.
} 
insurance programs. However, in operating the traditional agricultural insurance, it will face up moral hazard and adverse selection. Moral hazard refers to the insured person's optimal decision may change as a result of taking out insurance[2]. Adverse selection means that people who are more likely to suffer the insured event will be more willing to insure at a give rate[2]. Both moral hazard and adverse selection occur because of asymmetric information. As the traditional agricultural insurance's payout is linked with farmers' individual-losses, farmers will show an adverse selection behavior tend to grow the crop with high income but vulnerable to natural disaster. After purchasing insurance, farmers will not actively seek ways to protect insured crop from disasters, this is thought to be moral hazard behaviors. These two behavior will let agriculture insurance company face the compensation pressure and even lead to a failure of agricultural insurance market. Moreover, the geographical dispersion of agriculture production makes the operational and administrative costs of delivering insurance high in comparison with other types of insurance [3]. Weather index insurance is novel type of insurance contract for smallholder farmers and other rural inhabitants affected by uninsured covariate weather risks. It links insurance payout from weather event(temperature, precipitation, wind) that are defined and recorded over a pre-specified period of time at local weather station. Weather index insurance contract is typically written for a single peril such as temperature, the weather risk of greatest concern to local different crop production. For example, the first weather index insurance contract in Anhui Province, China insured against late spring coldness for wheat farmers as assessed by temperature in spring. On the other hand, another weather index insurance in Wuhu, Anhui Province is implemented for rice farmers against the local high temperature temperature in summer. Compared with traditional agricultural insurance, weather index insurance selects weather index as subject matter of insured, which can not be controlled by people's behavior, so it is recognized as having the advantages of reducing operating costs, avoiding moral hazard and adverse selection. China, like many other countries, starts to focus on weather index insurance to hedge weather risk in agriculture. In 2007, China piloted its first agricultural weather index insurance in Shanghai. Recently, Chinese government has successively introduced relevant policy to promote the development of weather index insurance in agriculture. By 2019, the pilots of weather index insurance in China has been expanded to include 16 regions, and covered different types of crops, such as rice, wheat, apple and tobacco. In spite of increasing numbers of pilot areas in China, take-up has been disappointing low in many other developing countries. Therefore, the purpose of this paper is firstly, selects one of weather index insurance pilot areas- Jiangxi Province as research object to explore the status of weather index insurance and its processing problems through the factors influencing farmers' willingness to pay for Low Temperature Index-based Mandarin Orange Insurance in the pilot area. Secondly, to identify problems in the pilot process and make appropriate countermeasures and relevant suggestions to insurance company to improve insurance product design and help the government to re-think the next phase of development of weather index insurance program.

It's not surprise that there is growing numbers of literatures on farmers' preference and willingness to buy weather-index insurance. These researches are divided into two types. One type of the literatures focus on identifying factors that influence farmers' preference to pay for weather index insurance based on contingent valuation (CV). The other type of studies target farmers' satisfaction with current weather index insurance in the pilot areas. The results of both types of studies aim to help insurance company, government 
and institution have a good understanding of how to design products, implement a policy and provide subsidies to attract more farmers to participate in this scheme. It is possible that farmers simply avoid a very high premium on the insurance they were offered [4,5,6,7], as well as a clear preference for insurance contracts with higher payouts[8]. The participants may not have placed a high value on the insurance if they realized that weather recorded at the reference weather station was not highly correlated with weather index on their own plot, i.e., basis risk was very high $[4,9,10,11,12,13,14]$. In the investigations, lacking of trust in insurance providers is also a key factor negatively influence the demand for weather index insurance[15]. In the aspect of subsidy, Wang HH [16] addressed that in order for wide spread adoption of weather insurance farmers will require an 80 per cent discount or subsidy to current crop insurance initiatives. Petri Liesivaara, Sami Myyrä [17] stated the prospect of government disaster relief affects the willingness to pay for crop insurance products. Many scholars tried to find other factors that influence farmer's decisions on purchasing weather index insurance. Anthony Patt [8] suggested a better understanding of basic insurance concepts with greater willingness to purchase index insurance. Ruth Vargas Hill [12] finds that educated, wealthier individuals are more likely to purchase insurance. Ntukamazina $\mathrm{N}$ [5] suggested that the age of farmers, land tenure and farm size have negative impact on the uptake of these products.

The literatures summarized the factors affecting the purchase of weather index insurance from different perspective, however, mostly based on data-set observations with discrete choice experiment. The innovation of this study is firstly attempt Fuzzy-Set Qualitative Comparative Analysis (fsQCA) to field visits, interviews and discussions with insured farmers to explore the farmer's attitude with Low Temperature-Index based Mandarin Orange Insurance in Jiangxi Province, China. The result will further provide some certain references for Jiangxi Province and other regions of agricultural weather index insurance pilot in China, so as to suggest ways of improving insurance uptake.

The rest of this paper is organized as follows. Section 2 presents research design, which includes overview of Low Temperature Index-based Mandarin Orange Insurance in Jiangxi Province, questionnaire design and data collection. Section 3 explains FuzzySet Qualitative Comparative Analysis(fsQCA) method. Section 4 reports the main results and discussion. Lastly, Section 5 contains the conclusions and recommendation of this study.

\section{Research design}

\subsection{Overview of Low Temperature Index-based Mandarin Orange Insurance in Jiangxi Province}

Nanfeng County is located in the southeast of Jiangxi Province (Figure-1). It consists of 10 towns with 140 villages. As one of the most important producing areas of mandarin orange in China, mandarin orange production contributes $80 \%$ to total farmland and already become pillar industry here.

The topography of Nanfeng County is dominated by hills. Mandarin orange is extensively grown on the hills. As mandarin orange market expansion and its increasing profit, farmers expanded cultivated areas of mandarin orange to their cropland in Nanfeng County. Both hills and cropland are suitable for mandarin orange growth and the 
topographical variation will not affect mandarin orange production. Among natural factors, mandarin orange cultivation is highly dependent on the temperature, especially the low temperature in winter.

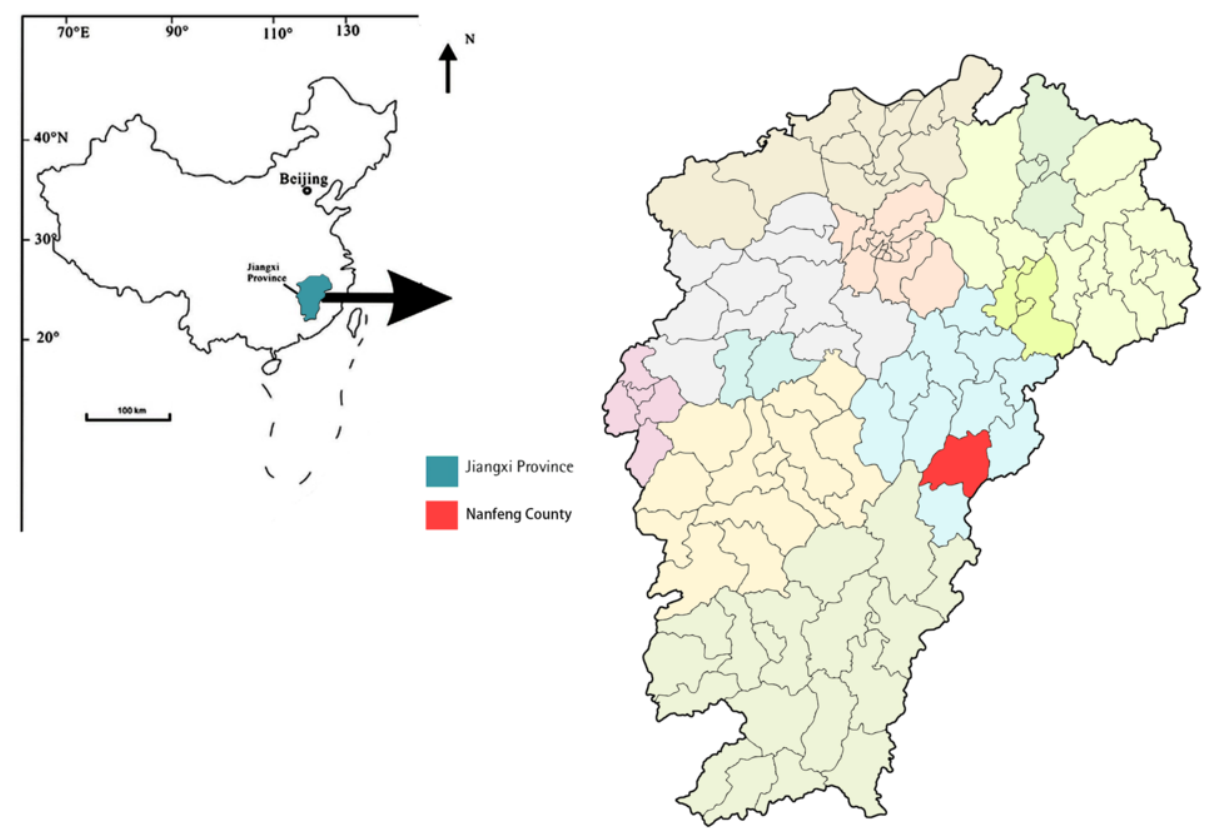

Figure 1. Location Map of Nanfeng county in Jiangxi Province, China

In order to help farmers against low temperature, the People's Insurance Company (Group) of China (PICC) of Jiangxi Branch cooperated with the Jiangxi Provincial Climate Center to implement Low Temperature Index-based Mandarin Orange Insurance (LTIMOI) in Nanfeng County, which covered mandarin overwintering stage from December to February of the following year. Low Temperature Index-based Mandarin orange (LTIMOI) was started in 2011 with underwritten areas of 28,400 mu(667 $\left.\mathrm{m}^{2}\right)$ and premium income of $2.3156 \mathrm{CNY}$ million.

The insurance policy period lasts up 1 year, from March to February of the following year. Considering effects of various temperatures on mandarin orange in winter, LTIMOI contract sets 11 strike levels and mandarin orange farmers can select to buy insurance at threshold of $-1^{\circ} \mathrm{C}$ or $-4^{\circ} \mathrm{C}$ based on their own experience. The premium was initially set as $72 \mathrm{CNY} / \mathrm{mu}$ and now is increased to $100 \mathrm{CNY} / \mathrm{mu}$ for every farmer. As a Policyoriented agricultural insurance, Jiangxi governments directly subsided premiums for insurance company with total subsidy ratio of $40 \%$. Farmers bear $60 \%$ of premium, ie. $100 \mathrm{CNY}$. According to the insurance contract, if the daily minimum temperature falls below (inclusive) the threshold, a pay-out is triggered for all farmers holding a contract with reference to the particular weather station. The maximum pay-out is 2,000 CNY $/ \mathrm{mu}$, and pay-out for each strike levels follows the formula of maximum payout per mu multiplies a given premium ratio. The details about thresholds and payout are shown in Table-1. 
Table 1. The pay-out stage of Low Temperature Index-based Mandarin Orange Insurance

\begin{tabular}{|c|c|c|}
\hline Daily Minimum Temperature & No.1 Pay-out Phase & No.2 Pay-out Phase \\
\hline (DMT)and Duration & $\mathrm{DMT} \leq-1^{\circ} \mathrm{C}$ & $\mathrm{DMT} \leq-4^{\circ} \mathrm{C}$ \\
\hline$-2^{\circ} \mathrm{C}<\mathrm{DMT} \leq-1^{\circ} \mathrm{C}$ & Per Mu of Pay-out*4\% & \\
\hline$-3^{\circ} \mathrm{C}<\mathrm{DMT} \leq-2^{\circ} \mathrm{C}$ & Per Mu of Pay-out $* 5 \%$ & \\
\hline$-4^{\circ} \mathrm{C}<\mathrm{DMT} \leq-3^{\circ} \mathrm{C}$ & Per Mu of Pay-out $* 6 \%$ & \\
\hline$-5^{\circ} \mathrm{C}<\mathrm{DMT} \leq-4^{\circ} \mathrm{C}$ & Per Mu of Pay-out $* 7 \%$ & Per Mu of Pay-out $* 4 \%$ \\
\hline $\begin{array}{c}-6^{\circ} \mathrm{C}<\mathrm{DMT} \leq-5^{\circ} \mathrm{C} \\
\text { and Duration }<3 \text { hours }\end{array}$ & Per Mu of Pay-out $* 8 \%$ & Per Mu of Pay-out $* 5 \%$ \\
\hline $\begin{array}{l}-6^{\circ} \mathrm{C}<\mathrm{DMT} \leq-5^{\circ} \mathrm{C} \\
\text { and Duration geq } 3 \text { hours }\end{array}$ & Per Mu of Pay-out $* 10 \%$ & Per Mu of Pay-out $* 6 \%$ \\
\hline $\begin{array}{c}-8^{\circ} \mathrm{C}<\mathrm{DMT} \leq-6^{\circ} \mathrm{C} \\
\text { and Duration }<3 \text { hours }\end{array}$ & Per Mu of Pay-out $* 20 \%$ & Per Mu of Pay-out $* 15 \%$ \\
\hline $\begin{array}{l}\qquad-8^{\circ} \mathrm{C}<\mathrm{DMT} \leq-6^{\circ} \mathrm{C} \\
\text { and Duration geq } 3 \text { hours }\end{array}$ & Per Mu of Pay-out $* 30 \%$ & Per Mu of Pay-out $* 20 \%$ \\
\hline $\begin{array}{l}-10^{\circ} \mathrm{C}<\mathrm{DMT} \leq-8^{\circ} \mathrm{C} \\
\text { and Duration }<3 \text { hours }\end{array}$ & Per Mu of Pay-out $* 50 \%$ & Per Mu of Pay-out $* 30 \%$ \\
\hline $\begin{array}{l}-10^{\circ} \mathrm{C}<\mathrm{DMT} \leq-8^{\circ} \mathrm{C} \\
\text { and Duration geq3 hours }\end{array}$ & Per Mu of Pay-out $* 70 \%$ & Per Mu of Pay-out $* 60 \%$ \\
\hline $\mathrm{DMT} \leq 10^{\circ} \mathrm{C}$ & Per Mu of Pay-out $* 100 \%$ & Per Mu of Pay-out $* 100 \%$ \\
\hline
\end{tabular}

Source: the content is provided by PICC of Jiangxi Branch

The data in Figure-2 shows the underwritten areas and premium income of LTIMOI from 2011 to 2018. We can find it presents an encouraging take-up from 2011 to 2015 , but the purchasing for LTIMOI sharply decreased after 2015, and even almost no farmers bought this insurance in 2018. This surprising result gives us an access to explore the reason for the disappointing take-up of LTIMOI. The reason will be explained by applying collected data to fsQCA analysis methodology and the more detail will be showed in next sections.

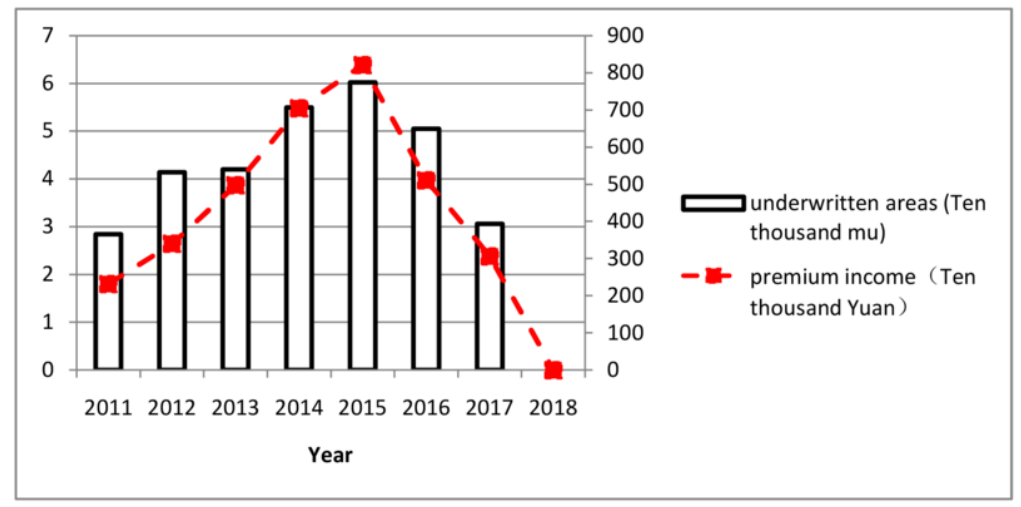

Source: the data is collected by authors from the survey in Nanfeng County

Figure 2. The underwritten areas and premium income of Low Temperature Index Insurance-based Mandarin Orange in Nanfeng County 


\subsection{Questionnaire design}

The questionnaire of farmers' willingness to pay for LTIMOI consists of two parts. The first part is asked for socio-demographic characteristics information about mandarin orange farmers' education level, planting experience, farmland cultivated, total planting cost and annual net income. The second part focuses on the factors influencing farmer's willingness to purchase weather index insurance depend on a review of relevant literature. We made five aspects of influencing factors based on farmers' perspectives in Nanfeng County, which conducted as casual conditions in the data analysis. These casual conditions are: insurance product design(strike level), Price-performance ratio(premium and payout), Do I need this insurance product( planting cost, effect of low temperature on mandarin orange planting), After-sales(claim settlement processes, trust in insurance company), and government subsidy. The outcome condition is farmers' willingness to purchase insurance. Figure-3 shows independent conditions and outcome condition, and we use weather to instead of effect of low temperature on mandarin orange planting.

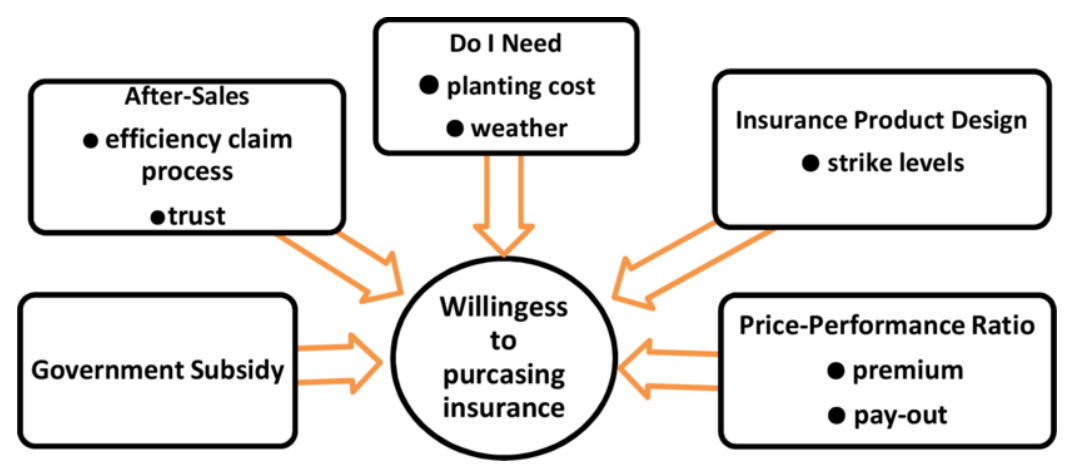

Figure 3. The Casual Conditions and Outcome Condition

We performed 5 point Likert scale to the casual condition. For example, the answer of strike level was rated on a scale anchored by 1, "very accurate"; 2, "accurate"; 3, "neutral"; 4, "inaccurate"; 5,"very inaccurate". The outcome condition of farmers' willingness to purchasing LTIMOI is measured by 3 point Likert scale using purchasing for a value of 1 ; thinking for a value of 2 and don't want to purchase for a value of 3 . The Likert scale of casual conditions and outcome condition is showed in Figure-4.

\subsection{Data collection}

This survey was undertaken 6 villages in Nanfeng County based on field visits, interviews and discussions with insured farmers, who were insured at the time of the survey or had purchased an insurance contract in previous years. The data was collected from November 9, 2019, to January 18, 2020 and covered 360 people. Finally, we got valid questionnaire from 110 people. In order to ensure the accuracy of the investigation, the surveyed people are all men with the age among 45-60. This is because in the rural areas of Nanfeng County, the farmer households still follow the traditional customs of the "male breadwinner and female homemaker". In addition, the young people, whose age is among 28-40 are migrant workers in the city. Therefore, both female and young people seldom know the details about index insurance. 


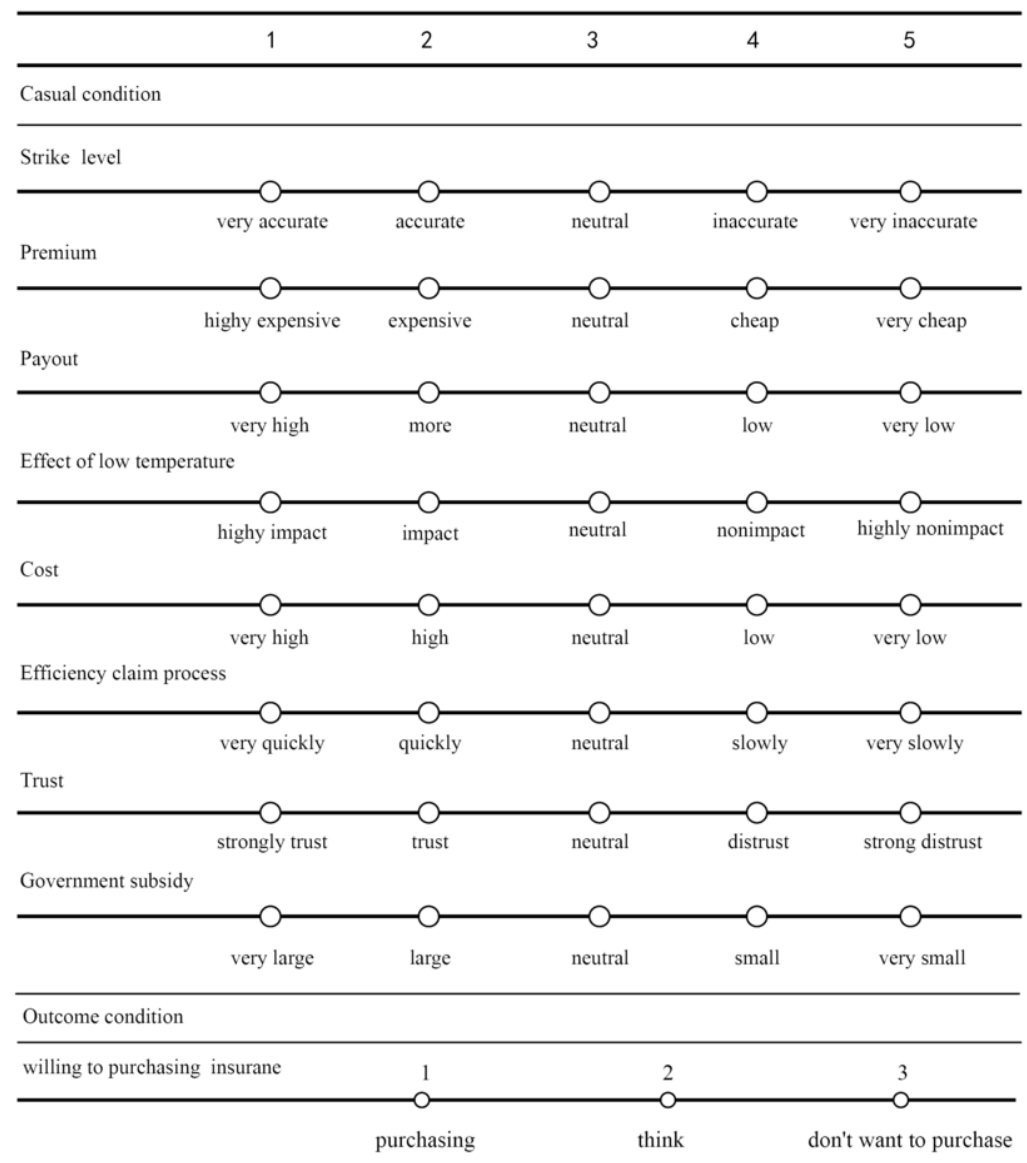

Figure 4. The Likert Scale of Casual Conditions and Outcome Condition

\section{Method}

\subsection{Fuzzy-Set Qualitative Comparative Analysis method}

We adopt Fuzzy-set Qualitative Comparative Analysis (fsQCA) to surveyed data of second part of the questionnaire analysis. FsQCA is derived from Qualitative Comparative Analysis (QCA), which is proposed by Ragin. QCA builds on the logic of qualitative, case-oriented research as it is practiced in comparative sociology and comparative politics and uses set-theoretic methods of comparison, representing each case as a combination of causal and outcome conditions [18]. The distinct advantage of QCA method is that it combines the advantages of both qualitative and quantitative analysis. For example, QCA begins with a bottom-up approach that pieces case together to illustrate a grander pattern, and then as in quantitative research, QCA uses stepwise paired comparisons strategically simplify complexity and expose various patterns within a system [19].

fsQCA overcomes the binary classification in QCA, and describes cases as the combination of causal conditions and the outcome, rather than constituting just a single con- 
dition [20]. Moreover, fsQCA allows analysis with both small sample size and large sample size. Calibration is core task of fsQCA. It transforms ordinal scales or continuous data into numbers expressing the degree of membership to the sets that represent the conditions under study [21]. All fuzzy-set values for all simple conditions range from 0 to 1 [21], and these values indicate the degree of membership to each set representing each condition [22].

The steps to applying an fsQCA for data analysis are as follows: (1) transform variables to calibrate. (2) perform the analysis of necessity; and (3) perform the analysis of sufficiency[23].

\subsection{Calibration of original data}

As mentioned above, the key step in fsQCA analysis should transform variables into calibrated, we directly assigned calibration to both independent measures and outcome condition which follow Ragin (2008). A continuous-fuzzy set and are made for independent measures: "1, 2, 3, 4, 5" (five point scare) to " $0,0.2,0.4,1$ " (continuous-fuzzy membership) and three values fuzzy set for outcome condition: "1, 2, 3" (three point scare) to " $0,0.5,1$ " (three values fuzzy membership). Table- 2 shows the result of calibration of independent measures and outcome condition.

Table 2. The Calibration of casual conditions and outcome condition

\begin{tabular}{|c|c|c|c|c|c|}
\hline & \multicolumn{5}{|c|}{ Calibration } \\
\hline $\begin{array}{c}\text { variable of } \\
\text { casual condition }\end{array}$ & 0 & 0.2 & 0.4 & 0.6 & 1 \\
\hline strike level & very accurate & accurate & Neither accurate nor inaccurate & inaccurate & very inaccurate \\
\hline premium & highly expensive & expensive & Neither expensive nor cheap & cheap & very cheap \\
\hline payout & very high & more & Neither high nor low & low & very low \\
\hline Weather & highly impact & impact & Neither impact nor nonimpact & nonimpact & highly nonimpact \\
\hline $\begin{array}{c}\text { efficiency } \\
\text { claim process }\end{array}$ & very quickly & quickly & Neither quickly and slowly & slowly & very slowly \\
\hline cost & very high & high & Neither high nor low & low & very low \\
\hline trust & strongly turst & trust & Neither trust nor distrust & distrust & strongly distrust \\
\hline government subsidy & very large & large & Neither large not small & small & very small \\
\hline outcome condition & 0 & 0.5 & 1 & & \\
\hline $\begin{array}{c}\text { willingness to } \\
\text { purchasing insurance }\end{array}$ & purchasing & thinking & don't want to purchase & & \\
\hline
\end{tabular}

\section{Empirical results}

\subsection{Characteristics of sample farmers}

This study obtains usable information of mandarin orange cultivation from questionnaires and interview and discussion with farmers. Table-3 is demographic and agronomic information of surveyed mandarin orange farmers in Nanfeng County. 
It is clearly find that $90 \%$ mandarin farmers with lower education level. Only $8 \%$ and $2 \%$ reached high school degree and college degree, respectively. Nanfeng County has a long history of planting mandarin orange, so the information in Table-3 shows all the farmers have rich plant experience in mandarin orange cultivation: $85 \%$ have 15 years20 years; and $15 \%$ have 20 years-30 years. Every household plants mandarin orange here, but the land cultivated are typical smallholders, $75 \%$ with planting size of around $5 \mathrm{mu}-10 \mathrm{mu}, 20 \%$ with farmland size of $10 \mathrm{mu}-15 \mathrm{mu}$, only $5 \%$ farmer has $50 \mathrm{mu}-60 \mathrm{mu}$ farmland. The main planting cost of mandarin orange consists of graft cost, pesticide and fertilizer costs and labor cost. Table-3 exhibits the $75 \%$ total planting cost of mandarin orange are around 20,000 CNY-30,000 CNY, which is consistent with small-scared household farmer's mandarin orange planting areas. The surveyed farmers also reported planting cost of mandarin orange has continued to increase these years, meanwhile, its wholesales price decreases. Figure-5 shows the wholesale price of mandarin orange in Nanfeng County recent years. In the Figure-5, we can clearly find that the wholesale price of mandarin orange has continued to fall. In 2019, the wholesales price even falls to $0.5 \mathrm{CNY} / \mathrm{Catty}$. Mandarin orange planting is the major source of income for farmers in Nangfeng County. The information in Table-3 indicates annual net income of most of mandarin orange planting households is ranged from a low of 20,000 CNY-30,000 CNY. $20 \%$ of households' annual net income is around 50,000 CNY-60,000 CNY and only 5\% of households have a net income more than 100,000 CNY.

Table 3. The demographic and agronomic information of surveyed mandarin farmers $(\mathrm{N}=110)$

\begin{tabular}{cccc}
\hline Level of Education $(\%)$ & \multicolumn{3}{c}{ Plant Experience $(\%)$} \\
\hline Junior high school or less & 90 & 10 years 15 years & 10 \\
high school & 8 & 15 years 20 years & 75 \\
collage & 2 & 20 years 30 years & 15 \\
\hline Farmland Cultivated $(\%)$ & \multicolumn{3}{c}{ Total Planting Cost $(\%)$} \\
\hline 5 mu $\sim 10 \mathrm{mu}$ & 75 & $20,000 \mathrm{CNY} \sim 30,000 \mathrm{CNY}$ & 75 \\
$10 \mathrm{mu} \sim 15 \mathrm{mu}$ & 20 & $40,000 \mathrm{CNY} \sim 50,000 \mathrm{CNY}$ & 20 \\
$20 \mathrm{mu}$ or more & 5 & more than $60000 \mathrm{CNY}$ & 5 \\
\hline Annual Farmer Net Income $(\%)$ & & & \\
\hline 20,000 CNY $\sim 30,000 \mathrm{CNY}$ & 75 & & \\
$50,000 \mathrm{CNY} \sim 60,000 \mathrm{CNY}$ & 20 & & \\
more than $100,000 \mathrm{CNY}$ & 5 & & \\
\hline
\end{tabular}

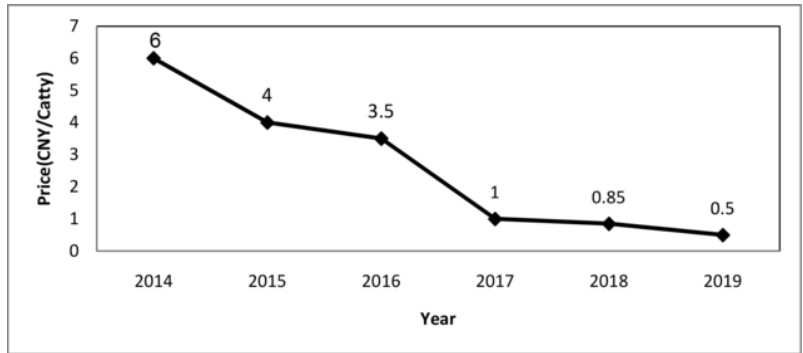

Source: the data is collected by authors from the survey in Nanfeng County

Figure 5. The Wholesales Price of Mandarin Orange in Nanfeng County 


\subsection{FsQCA result}

\subsubsection{Descriptive statistic}

Table-4 presents descriptive statistic of both casual conditions and outcome condition. According to calibration of original data, it clearly shows that almost all the people select 'don't want to purchase insurance' when filling in the questionnaire and all the farmers in the survey express their distrust of insurance company. Most of farmers consider the design of LTIMOI is neither accurate nor inaccurate. Farmers' attitudes toward the effect of low temperature are more inclined to 'nonimpact'. The descriptive statistic shows that most of farmers think the premium of LTIMOI is expensive. In addition, its claim process of is not efficient and the compensation is negligible compared to the planting cost. Moreover,the subsidy from government is not enough.

Table 4. Descriptive statistic of calibration of original data

\begin{tabular}{ccccc}
\hline Variable & Mean & STd.Dev & Minimum & Maximum \\
\hline strike level & 0.46 & 0.13 & 0.2 & 0.6 \\
premium & 0.31 & 0.16 & 0.2 & 0.6 \\
pay-out & 0.57 & 0.22 & 0.2 & 1 \\
cost & 0.25 & 0.19 & 0 & 0.6 \\
weather & 0.56 & 0.26 & 0 & 1 \\
efficiency & 0.58 & 0.3 & 0 & 1 \\
subsidy & 0.57 & 0.06 & 0.4 & 0.6 \\
trust & 1 & 0 & 1 & 1 \\
willingness & 0.94 & 0.19 & 0 & 1 \\
\hline
\end{tabular}

\subsubsection{Necessity analysis}

Following the second step of fsQCA analysis, the necessity analysis of the casual conditions for the outcome condition is tested. The consistency determines whether the casual condition is necessary condition for outcome condition or not. According to Schneider [23] stated in his study, if the consistency score exceeds the threshold of 0.9, it can explain a condition is 'necessary' or 'almost necessary'. As presented in Table-5, only the consistency of 'trust' exceeds 0.9 this requirement. This result indicates the trust in insurance company is highly associated with LTIMOI purchases.

Table 5. The necessity analysis of casual condition for the outcome condition

\begin{tabular}{ccc}
\hline Condition & Consistency & Coverage \\
\hline Strike Level & 0.48 & 0.98 \\
Premium & 0.72 & 0.97 \\
Pay-out & 0.60 & 0.98 \\
Cost & 0.62 & 0.95 \\
Weather & 0.24 & 0.96 \\
Efficiency & 0.52 & 0.99 \\
Trust & 0.92 & 0.96 \\
Government Subsidy & 0.59 & 0.97 \\
\hline
\end{tabular}




\subsubsection{Results of configurations}

Next, the results of configurations through the truth table based on the calibration of original data is performed. Table- 6 presents five configurations of 8 casual conditions. Following Ragin and Fiss [24] suggestion, in Table-6, the black circle (' $\bullet$ ') indicates presence of a condition. Circle with a cross out (' $\otimes$ ') denotes absence of a condition and the white circle (' $\circ$ ') indicates a situation of either present or absent, which is not care. All configurations in Table- 6 are meaningful and empirically important because their unique coverage is more than 0 . Furthermore, these configurations show a consistency score of $0.62 \%$ and the solution consistency of 0.96 , which means the explanation of those casual outcomes on the effect of willingness to insurance purchase is relative high.

The first configuration indicates the combination of expensive premium, low payout, high planting cost, no effect of low temperature, low subsidy from government and distrust of insurance company result in $\mathrm{w}=1$, that is mandarin farmers are unwilling to buy LTIMOI. In contrast, the second configuration shows the opposite pattern with absence of premium and presence of strike level. The third configuration exhibits inaccurate strike level, low indemnity, high planting cost, slow efficiency claim processes, insufficient government subsidy and distrust will influence farmers to buy insurance. Comparing third configuration and fourth configuration indicate that combination of expensive premium, less payout, higher planting cost, low government subsidies and distrust of insurance company will lead to farmers' unwillingness to buy weather index insurance. The fifth configuration indicates a third path to farmers' dissatisfaction with insurance, combining only weather, smaller subsidy from government and distrust of insurance company.

Table 6. FsQCA result

\begin{tabular}{|c|c|c|c|c|c|}
\hline \multirow{2}{*}{ Configurations } & \multicolumn{5}{|c|}{ solutions } \\
\hline & 1 & 2 & 3 & 4 & 5 \\
\hline \multicolumn{6}{|l|}{ Insurance product Design } \\
\hline Strike level & $\otimes$ & $\bullet$ & $\bullet$ & $\circ$ & $\otimes$ \\
\hline \multicolumn{6}{|l|}{ Price-performance ratio } \\
\hline Premium & $\bullet$ & $\otimes$ & $\bullet$ & $\bullet$ & $\otimes$ \\
\hline Payout & $\bullet$ & $\bullet$ & $\bullet$ & $\bullet$ & $\otimes$ \\
\hline \multicolumn{6}{|l|}{ Do I need } \\
\hline planting cost & $\bullet$ & $\bullet$ & $\bullet$ & $\bullet$ & $\otimes$ \\
\hline weather & $\bullet$ & $\bullet$ & $\bullet$ & $\otimes$ & $\bullet$ \\
\hline \multicolumn{6}{|l|}{ After sales } \\
\hline efticiency claim process & $\otimes$ & $\circ$ & $\circ$ & $\otimes$ & $\otimes$ \\
\hline trust & $\bullet$ & $\bullet$ & $\bullet$ & $\bullet$ & $\bullet$ \\
\hline Government subsidy & $\bullet$ & $\bullet$ & $\bullet$ & $\bullet$ & $\bullet$ \\
\hline Raw coverage & 0.14 & 0.16 & 0.21 & 0.42 & 0.28 \\
\hline unique coverage & 0.05 & 0.01 & 0.05 & 0.06 & 0.01 \\
\hline Cosistency & 0.92 & 0.93 & 0.90 & 0.98 & 1 \\
\hline \multicolumn{6}{|c|}{ overall solution coverage: 0.62} \\
\hline \multicolumn{6}{|c|}{ overall solution cosistency: 0.94} \\
\hline
\end{tabular}




\subsection{Discussion}

Table-5 and Table- 6 show that interviewed people are not willing to buy LTIMOI again. According to the result, we found the pilot of LTIMOI is not successful in Nanfeng County. The reason for unsuccessful pilot dues to expensive premium, lower indemnity, high planting cost, low government subsidy and distrust of insurance company, which is indicated by the fourth configuration.

From Table-6, clearly, distrust in insurance company is the core factor that influences farmers' purchasing for insurance. It is very common phenomenon that migrant workers entrust their own mandarin orange cultivation to other farmers in Nanfeng County. The farmers purchased insurance for the entrusted mandarin orange trees, however, with the name of migrant worker in the insurance policy. Most of migrant workers didn't know their mandarin orange trees are insured when insurance company return insured farmers who received payout. Therefore, without any investigation, insurance company has identified this common phenomenon as 'fraud'. Many farmers didn't receive payout for this event. Because of information asymmetry, insurance company and farmers lost trust in each other. This also can explain why all the surveyed famers selected fully distrust in the questionnaire.

The key reason for farmers not to purchasing LTIMOI is expensive premium, lower indemnity and high planting cost of mandarin orange. Farmers emphasized these three points when filling out the questionnaire. In Table-3, it is clearly find that the planting cost of mandarin orange is relative high because of both low net income and cheap wholesales price of mandarin orange. For example, in 2013, the temperature in winter reached $-8^{\circ} \mathrm{C}$ and caused frost. In 2013, the income of mandarin orange is about 2,400 $\mathrm{CNY} / \mathrm{mu}$ and the total cost of planting mandarin orange is about $1,557.23 \mathrm{CNY} / \mathrm{mu}$ based on farmers' memories. In addition, premium of LTIMOI at that time is $72 \mathrm{CNY}$ $/ \mathrm{mu}$. Therefore, the payout at strike level of $-8^{\circ} \mathrm{C}$ is obviously not enough for farmers. On the other hand, the frost will directly lead to large-scare death of the mandarin trees, and farmers should repurchase seedlings to plant the mandarin tress. This will take at least 3 years- 4 years for mandarin orange tree to bear fruit. Except that farmers have to pay high cost of mandarin orange production during this period, farmers cannot earn income from mandarin orange. According to the analysis above, the total economic loss of mandarin with higher planting cost even can't be made up for the maximum payouts of 2,000 CNY/mu.

Government support plays a key role in agricultural insurance, especially when concerning premiums on agricultural insurance subsidies. The expensive premium of LTIMOI is closely related to smaller government subsidy. Government directly subsidizes premium for PICC of Jiangxi Branch, but with only $40 \%$ subsidy ratio. Table-7 is agricultural insurance premium rate table of PICC in Jiangxi Province. From Table-7, it is clearly find that compared with premium and subsidy ratio of other crop insurance in Jiangxi Province, the price of LTIMOI is more expensive and government subsidy is relative low. Regarding high planting cost and cheap wholesales price of mandarin orange, farmers don't want to spend more money on LTIMOI with lower indemnity.

Another main reason for farmers not willing to buy this insurance is strike level and effect of low temperature. As climate warms, drought and precipitation becomes main weather risk for mandarin orange, so the daily minimum temperature threshold is difficult to reach these two strike levels of $-1{ }^{\circ} \mathrm{C}$ and $-4{ }^{\circ} \mathrm{C}$. Furthermore, because of 
Table 7. The government subsidy for crops insurance in Jiangxi Province

\begin{tabular}{ccccc}
\hline Crop & Payout & Premium Rate & Subsidy ratio & Premium for famers \\
\hline rice & $400 \mathrm{CNY} / \mathrm{mu}$ & $5 \%$ & $75 \%$ & $5 \mathrm{CNY} / \mathrm{mu}$ \\
rape & $150 \mathrm{CNY} / \mathrm{mu}$ & $5 \%$ & $70 \%$ & $2.25 \mathrm{CNY} / \mathrm{mu}$ \\
peanut & $300 \mathrm{CNY} / \mathrm{mu}$ & $5 \%$ & $70 \%$ & $4.5 \mathrm{CNY} / \mathrm{mu}$ \\
\hline
\end{tabular}

Source: the subsidy is provided by government of Nanfeng County

basis risk, some insured farmers cannot get the payout even if strike level matches the low temperature risk of mandarin orange. Therefore, it is difficult to attract the farmers who had purchased this insurance to purchase it again and the farmers who insured at the time of survey regret purchasing LTIMOI, which is explained by fifth configuration. In addition, farmers more care about that if they can receive the payout regardless of whether the strike level or effect of temperature is appropriate or not, so both strike level and effect of low temperature becomes meaningless, as indicated by 'absence' or either present or absent in the configurations.

Claim processing efficiency is one of the advantages of weather index insurance. The LTIMOI contract states it will only take about one month for farmers to accept payout, but respondents felt that actually the claim process is complicated. At claim stage, not only do insured farmers need to provide various documents about their information of planting mandarin orange, but insurance company also have to check the number of acres of mandarin orange trees of insured farmers again. However, for farmers, they will more focus on whether payout can be paid rather than claim process efficiency. The farmers reported in the interview that as long as they can get pay-out, they can bear delay claim process. This is also why that among the configurations, claim process efficiency is expressed as 'absence' and 'either present or absent'.

Among the five configurations, the fifth configuration has highest values of consistency score of 1 . However, from the perspective of investigation, the fourth combination is more in line with reality, which can be seen as the most typical combination to explain the reason of low take up of LTIMOI these years in Nanfeng County.

\section{Conclusion and recommendations}

The primary objective of this study is to assess farmers' willingness to pay for Low Temperature Index-based Mandarin Orange Insurance and find out the problem in implementing this insurance product. We hope the key findings can promote the development of weather index insurance in Jiangxi Province and other regions in China. The result of fsQCA indicates a very low take-up for LTIMOI among farmers in Nanfeng County, Jiangxi Province. This can be contributed to three reasons. One reason is that in Nanfeng County, most of mandarin orange planting farmers are small-scared farmers, so under pressure of higher planting cost and lower wholesales price of mandarin, the high premium and low payout of LTIMOI as well as the changing weather risk are not sufficiently tailored to the needs and preferences of mandarin orange planting farmers. The other two reasons are that lacking of trust of insurance company and farmers cannot get strong support from government. The study puts forward to some recommendation from perspectives of contractual design and enhancing government support to help toward widespread insurance uptake among farmers. 
In response to changing weather risk, firstly, insurance company should add the designing of drought index and rainfall index in the insurance terms or design different weather index based on different weather risks in the mandarin orange's four stages of germination, growth, maturity and picking. Secondly, insurance company can set three different premium levels based on farmers' own land cultivated, the smaller the planting areas, the less premium are paid. In order to reduce basis risk in designing weather index, if the farmer who suffered loss without receiving compensation and they still want to continue buying insurance next year, insurance company can reduce a percentage of premium rate for them.

For solving the lacking of trust between insurance company and farmers, this problem, firstly, insurance salesman should improve their professional knowledge and business level and find ways to transparently and openly explain the insurance products to famers. Then, Insurance companies should promptly collect feedback from insured farmers, and incorporate valuable opinions into future insurance product design. On the other hand, farmers should promptly report relevant information on tangerine cultivation to insurance companies.

In China, weather index insurance program will not be improved significantly without strong government support. In order to reduce the basis risk in designing weather index insurance product, firstly, government should strengthen the infrastructure construction of rural weather meteorological stations to improve the meteorological data accuracy. Secondly, Jiangxi government should increase the proportion of provincial financial subsidies in Jiangxi Province to $30 \%$, or actively apply for financial subsidies from the central government for LTIMOI. Furthermore, in order to reduce disputes between insured farmers and insurance company, country-level government can establish communication intermediary between insurance parties.

Finally, establishing a three-party evaluation mechanism under the leadership of the China Insurance Regulatory to investigate and evaluate the financial data of insurance companies and farmers, respectively, which improve the risk protection ability of weather index insurance.

This paper points out the factors that influence the farmers' willingness to purchase LTIMOI of adopting surveyed data in fsQCA analysis, this study is not without limitations. Several limitations of this study to the need for future study. Firstly, the survey of this paper was only conducted in Jiangxi Province, the findings may be are not generalizable to other regions, especially developed regions in China. For this reason, further research will expand to other pilots in developed regions of China. Secondly, another limitation that comes with a small sample size of 110, which leads to smaller value of unique coverage in the fsQCA result. Therefore, the further work will increase with a higher sample size.

\section{Acknowledgment}

This research is supported by National Natural Science Foundation of China with Grants 71871233, Beijing Natural Science Foundation with Grants 9182015, National Social Science Foundation of China with Grants 9182015 and Research Foundation for Advanced Talents of East China University of Technology Grants NO.DHBK2019382. 


\section{References}

[1] Smit B, Cai Y. Climate change and agriculture in China. Glob Environ Chang. 1996 Jul;6(3):205-14.

[2] Quiggin J, Karagiannis G, Stanton J. Crop Insurance and Crop Production: An Empirical Study of Moral Hazard and Adverse Selection. Australian Journal of Agricultural Economics. 1993;37(2):95-113.

[3] Hohl RM. Agricultural insurance. In Hohl RM, editor. Agricultural Risk Transfer. New Jersey: John Wiley \& Sons; 2009. p. 149-87.

[4] Giné X, Yang D. Insurance, credit, and technology adoption: Field experimental evidencefrom Malawi. J Dev Econ. 2009 May;89(1):1-1.

[5] Ntukamazina N, Onwonga RN, Sommer R, Rubyogo JC, Mukankusi CM, Mburu J, Kariuki R. Indexbased agricultural insurance products: challenges, opportunities and prospects for uptake in sub-Sahara Africa. J Agric Rural Dev Trop Subtrop. 2017 Jul;118(2):171-185.

[6] Carter M, De Janvry A, Sadoulet E, Sarris A. Index-based weather insurance for developing countries: A review of evidence and a set of propositions for up-scaling. Develoment Policies Working Paper. 2014 Aug;111.

[7] Budhathoki NK, Lassa JA, Pun S, Zander KK. Farmers' interest and willingness-to-pay for index-based crop insurance in the lowlands of Nepal. Land Use Policy. 2019 Jun;85:1-0.

[8] Patt A, Peterson N, Carter M, Velez M, Hess U, Suarez P. Making index insurance attractive to farmers. Mitig Adapt Strateg Glob Chang. 2009 Dec;14(8):737-53.

[9] Clarke DJ. A theory of rational demand for index insurance. Am Econ J Microecon. 2016 Feb;8(1):283306.

[10] Gaurav S, Cole S, Tobacman J. Marketing complex financial products in emerging markets: Evidence from rainfall insurance in India. J Mark Res. 2011 Feb;48(SPL):S150-62.

[11] Takahashi K, Ikegami M, Sheahan M, Barrett CB. Experimental evidence on the drivers of index-based livestock insurance demand in Southern Ethiopia. World Dev. 2016 Feb;78:324-40.

[12] Hill RV, Hoddinott J, Kumar N. Adoption of weather-index insurance: learning from willingness to pay among a panel of households in rural Ethiopia. Agric Econ. 2013 Jul;44(4-5):385-98.

[13] Ntukamazina N, Onwonga RN, Sommer R, Rubyogo JC, Mukankusi CM, Mburu J, Kariuki R. Indexbased agricultural insurance products: challenges, opportunities and prospects for uptake in sub-Sahara Africa. J Agric Rural Dev Trop Subtrop. 2017 Jan;118(2):171-85.

[14] Fonta WM, Sanfo S, Kedir AM, Thiam DR. Estimating farmers' willingness to pay for weather indexbased crop insurance uptake in West Africa: Insight from a pilot initiative in Southwestern Burkina Faso. Agric Food Econ. 2018 Dec;6(1):11.

[15] Brans MV, Tadesse M, Takama T. Community-based solutions to the climate crisis in Ethiopia. In Fujikura R, Kawanishi M, editors. Climate Change Adaptation and International Development: Making Development Cooperation More Effective. London: Earth Scan; 2011. p. 217-38.

[16] Wang HH, Boyd M, Kong R, Turvey CG, He G, Ma J, Meagher P. Factors influencing Shaanxi and Gansu farmers' willingness to purchase weather insurance. China Agric Econ Rev. 2011 Nov;3(4):423-440.

[17] Liesivaara P, Myyrä S. The demand for public-private crop insurance and government disaster relief. J Policy Model. 2017 Jan;39(1):19-34.

[18] Ragin CC. Fuzzy Sets and Beyond. Chicago: University of Chicago Press; 2008. 240 p.

[19] Benney TM. Making Environmental Markets Work: The Varieties of Capitalism in the Emerging Economies. New York: Routledge; 2014. 156 p.

[20] Adame C, Caplliure EM, Miquel MJ. Work-life balance and firms: A matter of women?. J Bus Res. 2016 Apr;69(4):1379-83.

[21] Woodside AG, Zhang M. Cultural diversity and marketing transactions: Are market integration, large community size, and world religions necessary for fairness in ephemeral exchanges?. Psychol Mark. 2013 Mar;30(3):263-76.

[22] Domenech J, Escamilla R, Roig-Tierno N. Explaining knowledge-intensive activities from a regional perspective. J Bus Res. 2016 Apr;69(4):1301-6.

[23] Schneider MR, Schulze-Bentrop C, Paunescu M. Mapping the institutional capital of high-tech firms: A fuzzy-set analysis of capitalist variety and export performance. J Int Bus Stud. 2010 Feb;41(2):246-66.

[24] Fiss PC. Building better causal theories: A fuzzy set approach to typologies in organization research. Acad Manage J. 2011 Apr;54(2):393-420. 